\title{
An Improved Method for Fractionation of Small Quantities of Lettuce Latex
}

\author{
Thomas A. McKeon*, Jenny Brichta \\ USDA-ARS Western Regional Research Center, Albany, CA, USA \\ Email: *Thomas.mckeon@ars.us da.gov
}

How to cite this paper: McKeon, T.A. and Brichta, J. (2018) An Improved Method for Fractionation of Small Quantities of Lettuce Latex. American Journal of Plant Sciences, 9, 2004-2007. https://doi.org/10.4236/ajps.2018.910145

Received: September 30, 2017

Accepted: September 9, 2018

Published: September 12, 2018

Copyright $\odot 2018$ by authors and Scientific Research Publishing Inc. This work is licensed under the Creative Commons Attribution International License (CC BY 4.0).

http://creativecommons.org/licenses/by/4.0/

\section{cc) (i) Open Access}

\begin{abstract}
While large quantities of latex can be handled either by standard extraction techniques such as Soxhlet extraction or accelerated solvent extraction (ASE), smaller samples on the order of $0.3-0.5 \mathrm{~g}$ require handling on a microscale. We collected latex from lettuce plants in microcentrifuge tubes and, after drying under vacuum, resuspended the dried sample in acetone by holding in an ultrasonic cleaner. The resulting fine suspension was readily extracted with acetone and toluene to provide fractions representing the resin and rubber content of the latex. Using this approach, we compared latex from stems of bolting lettuce and from the floral stem of lettuce plants. While both types of stems contained a similar percentage of resin, the rubber content of the bolting stems exceeded that of the floral stems.
\end{abstract}

\section{Keywords}

Resin, Rubber, Isoprenoids, Lactuca sativa L. Solvent Extraction

\section{Introduction}

In efforts to develop new sources of natural rubber, a number of plants have been evaluated. Many plants secrete a latex that contains natural rubber, but only a limited number produce a rubber of sufficient quality to be useful for producing rubber products such as tires [1]. In addition to the standard commodity rubber derived from Hevea brasiliensis Mull. Arg., Parthenium argentatum A. gray (guayule), Taraxacum kok-saghyz (Russian dandelion), Lactuca serriola L. (wild lettuce) and Lactuca sativa L. (salad lettuce) all produce a suitable rubber for commercial use, with the latter four species suited for growth in temperate climates [2] [3].

The rubber content of lettuce latices has been previously reported. The rubber content of wild lettuce ranges from $2 \%$ to $8 \%$ [4] while carefully washed latex 
particles from both wild lettuce and salad lettuce (cv. Salinas) contain $54 \%$ and $47 \%$ rubber content based on products from acetone and dichloromethane extraction [3].

As part of an effort to understand the biosynthesis and regulation of rubber production, we have initiated research on lettuce as a simple model system for rubber biosynthesis, as it has two month growth time to bolting, with the stem being a good source of latex. As such, we have investigated latex production in bolting and flowering lettuce.

\section{Materials and Methods}

Plant growth: Romaine lettuce seeds, Parris Island Cos [5], were obtained locally and sourced from Cornucopia Seeds (Felton, CA, USA). Seeds were germinated on wet soil (Sunshine Mix \#1, Crop Production Services, Sacramento, CA, USA) with a light covering of sand, conditions that provided an $85 \%$ germination rate. When true leaves appeared and expanded, seedlings were transplanted to 18 liter pots containing the same soil with $50 \mathrm{ml}$ of slow release fertilizer added (Osmocote, 15-9-12, 8-9 month, Scotts-Sierra Horticultural Products Company, Marysville, $\mathrm{OH}, \mathrm{USA}$, full composition provided at https://icl-sf.com/us-en/products/ornamental_horticulture/osmocote-plus-stand ard-8-9-a903266-15-9-12/). Plants were grown under our standard greenhouse conditions with a temperature range of $17^{\circ} \mathrm{C}$ to $27^{\circ} \mathrm{C}$ with ambient springtime light. Humidity was not controlled but generally ranges from $40 \%$ to $70 \%$. The plants were maintained through bolting, flowering and seed maturity.

Latex collection: Latex was collected from the stems of bolting plants and from the stems bearing flowers. For collection from bolting stems, those stems bearing leaves, diagonal cuts were made in the stem and droplets collected in $2 \mathrm{ml} \mathrm{mi-}$ crocentrifuge tubes weighed prior to collection. Floral stems were cut completely just below the flower and latex droplets were collected in weighed $2 \mathrm{ml}$ microcentrifuge tubes. After collection, tubes were centrifuged in a microcentrifuge until the latex on the side of the tube was collected at the bottom and samples were held in a $-80^{\circ} \mathrm{C}$ freezer until needed.

Latex processing and extraction: Latex samples were dried to constant weight under vacuum in a dessicator, taking 1 to 2 days to reach dryness. Two $\mathrm{ml}$ of acetone was added to each tube and the samples were placed in an ultrasonic cleaner (Bransonic 12, Bransonic Cleaning Equipment Company, Shelton, CT, USA) until the latex sample was pulverized, approximately 10 - 30 minutes depending on the sample size $(0.3-0.5 \mathrm{~g})$. The suspension was poured into a $16 \times$ $100 \mathrm{~mm}$ screw cap tube, the microcentrifuge tube was rinsed with $2 \mathrm{ml}$ acetone and added to the screw cap tube, then held in the ultrasonic cleaner for $10 \mathrm{mi}$ nutes. The sample was centrifuged to pack the material $(10$ minutes, $1000 \mathrm{rpm}=$ $150 \mathrm{~g}$ at room temperature, $21^{\circ} \mathrm{C}$ ), the supernatant collected in another $16 \times 100$ $\mathrm{mm}$ screw cap tube and the solid material re-extracted 2 additional times with 2 $\mathrm{ml}$ acetone, held in the ultrasonic cleaner for 10 minutes and the acetone 


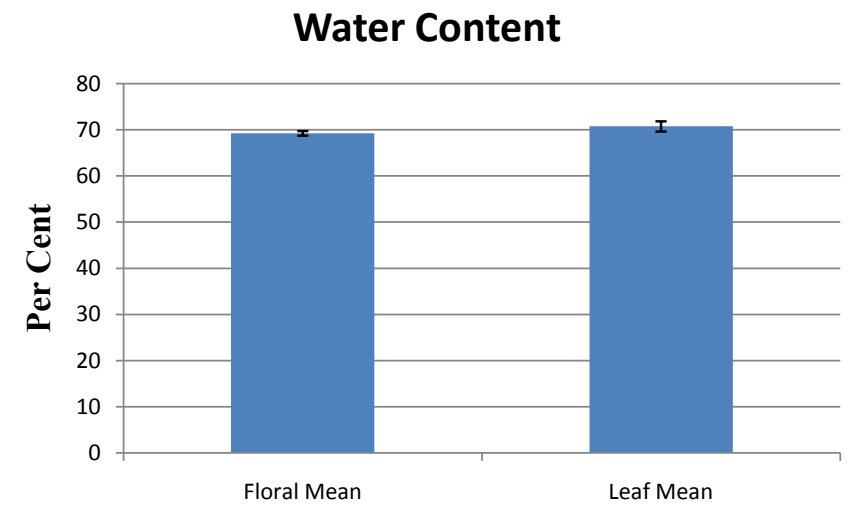

(a)

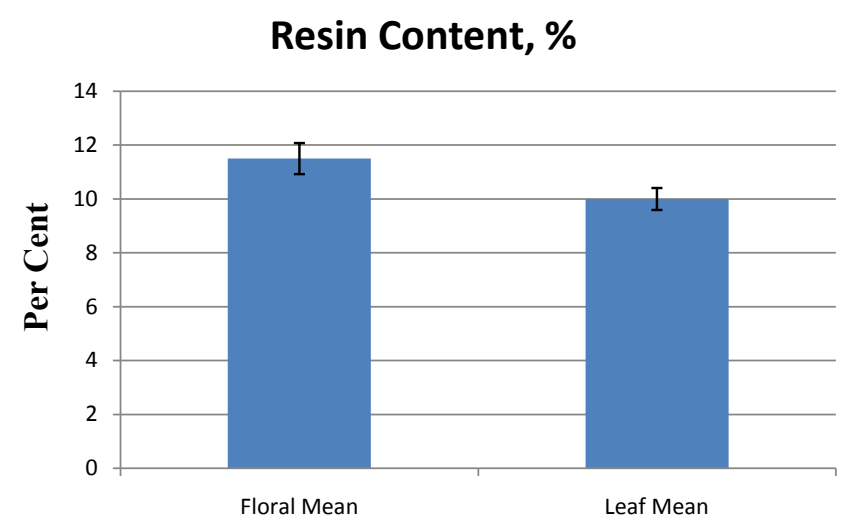

(b)

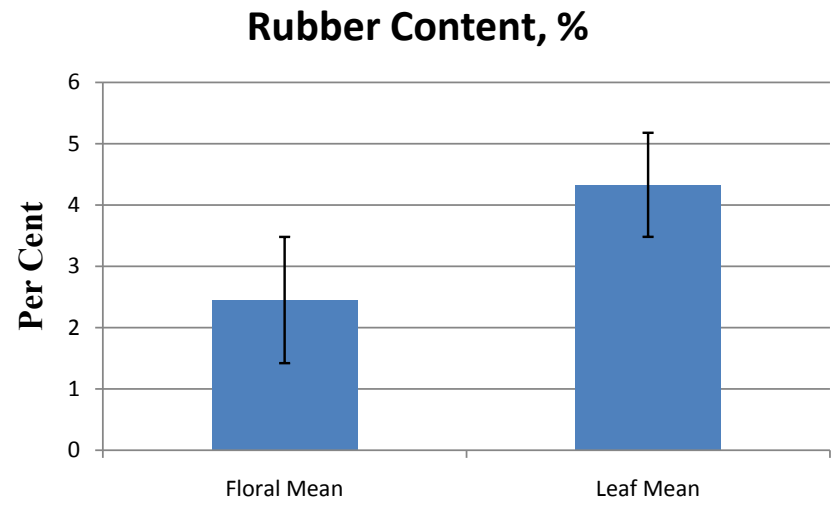

(c)

Figure 1. Constituents of latex derived from leaf stems and floral stems. Samples were processed as described in Materials and Methods and contents are presented as the mean of 4 samples based on w/w per cent.

supernatants pooled with the first supernatant. The pellet was re-extracted 3 times with $2 \mathrm{ml}$ toluene following the same procedure, pooling the 3 supernatants in the same $16 \times 100 \mathrm{ml}$ screw cap tube. The solvents were dried in weighed vials under nitrogen in a heating block and the contents determined by weight difference. Per cent water content was based on the weight difference from starting weight of latex to the water lost based on the dried weight, resin content (acetone extract) and rubber content (toluene extract) were based on final weight after solvent removal and the starting weight of the latex. Collected data were analyzed for average and standard deviation using Microsoft Excel.

\section{Results and Discussion}

Previous authors have noted some difficulty with extraction of lettuce latex and possibly latex from other plants as well. Fox [6] noted the resin forms a brittle material and an extraction procedure described for wild lettuce [4] uses stirring with a spatula and an extended extraction time to extract rubber from the pellet. The use of the ultrasonic cleaner pulverizes the hardened dry latex into fine particles and serves the same purpose as extended vortexing to extract the sample. While Soxhlet extraction and advanced solvent extraction (ASE) are very effec- 
tive for extraction of latex, use of the ultrasonic cleaner allows processing of small samples $(<0.1 \mathrm{~g})$ and obviates the expense of an ASE instrument.

The results of the lettuce leaf stem vs. floral stem latex comparisons are presented in Figures 1(a)-(c), presented as the mean of 4 determinations for each latex type. The water content of each sample is close, with the means for each near 70\% (Figure 1(a)). On the other hand, the floral stem has more resin, nearly $12 \%$ vs. $10 \%$ for the leaf stem (Figure $1(\mathrm{~b})$ ). The rubber content of the floral stem is lower than the leaf stem with a mean of $2.5 \%$ vs. $4.3 \%$ for the leaf stem (Figure 1(c)).

Rubber contents from each sample vary, with the range for the floral stem latex $1.3 \%$ to $3.7 \%$ rubber, while for the leaf stem the range is $2.8 \%$ to $6.7 \%$. If the water content is removed from the equation, as in Bushman et al. [3], the rubber content of the highest rubber content leaf stem latex is $40 \%$ while the highest rubber content floral stem latex is $25 \%$. In our experience, it is easier to collect latex from the leaf stem, and this appears to be the best source of rubber from lettuce. However, based on cross sectional area, the floral stem may have a higher percentage of laticifers, providing an advantage in biochemical studies.

\section{Conflicts of Interest}

The authors declare no conflicts of interest regarding the publication of this paper.

\section{References}

[1] Swanson, C.L., Buchanan, R.A. and Otey, F.H. (1979) Molecular Weights of Natural Rubbers from Selected Temperate Zone Plants. Journal of Applied Polymer Science, 23, 743-748. https://doi.org/10.1002/app.1979.070230309

[2] Metcalfe, C.R. (1966) Distribution of Latex in the Plant Kingdom. Economic Botany, 21, 115-127. https://doi.org/10.1007/BF02897859

[3] Bushman, B.S., Scholte, A.A., Cornish, K., Scott, D.J., Brichta, J.L., Vederas, J.C., Ochoa, O., Michelmore, R.W., Shintani, D.K. and Knap, S.J. (2006) Identification and Comparison of Natural Rubber from Two Lactuca Species. Phytochem, 67, 2590-2596. https://doi.org/10.1016/j.phytochem.2006.09.012

[4] Bell, J.L., Burke, I.C. and Neff, M.M. (2015) Genetic and Biochemical Evaluation of Natural Rubber from Eastern Washington Prickly Lettuce (Lactuca serriola L.). Journal of Agricultural and Food Chemistry, 63, 593-602. https://doi.org/10.1021/jf503934v

[5] Kristkova, E., Dolezalova, I., Lebeda, A., Vinter, V. and Novotna, A. (2008) Description of Morphological Characters of Lettuce (Lactuca sativa L.) Genetic Resources. HortScience (Prague), 35, 113-129. https://doi.org/10.17221/4/2008-HORTSCI

[6] Fox, C.P. (1913) Wild Lettuce Rubber. Journal of Industrial and Engineering Chemistry, 5, 477-478. https://doi.org/10.1021/ie50054a011 